International Journal of Environmental Research and

Public Health

ISSN 1660-4601

www.mdpi.com/journal/ijerph

Correction

\title{
Correction: Marcheggiani, S.; et al. Detection of Emerging and Re-Emerging Pathogens in Surface Waters Close to an Urban Area. Int. J. Environ. Res. Public Health 2015, 12, 5505-5527
}

\author{
Stefania Marcheggiani ${ }^{1, \dagger}, *$, Emilo D’Ugo ${ }^{1}$, Camilla Puccinelli ${ }^{1}$, Roberto Giuseppetti ${ }^{1}$, \\ Anna Maria D'Angelo ${ }^{1}$, Claudio Orlando Gualerzi ${ }^{2}$, Roberto Spurio ${ }^{2}$, Linda K. Medlin ${ }^{3,4}$, \\ Delphine Guillebault ${ }^{3,4}$, Julia Baudart-Lenfant ${ }^{4}$, Wilfried Weigel ${ }^{5}$, Karim Helmi ${ }^{6}$ and \\ Laura Mancini ${ }^{1, \dagger}$
}

1 Environmental, Quality and Fishfarm Unit, Environment \& Primary Prevention Department, Istituto Superiore di Sanità, Viale Regina Elena 299, 00161 Rome, Italy;

E-Mails: emilio.dugo@iss.it (E.D.); camilla.puccinelli@iss.it (C.P.); roberto.giuseppetti@iss.it (R.G.); annamaria.dangelo@iss.it (A.M.D.); laura.mancini@iss.it (L.M.)

2 Laboratory of Genetics, School of Biosciences and Veterinary Medicine, University of Camerino, Camerino, MC 62032, Italy; E-Mails: claudio.gualerzi@unicam.it (C.O.G.); roberto.spurio@iss.it (R.S.)

3 Microbia Environnement, Observatoire Océanologique, 66650 Banyuls/Mer, France;

E-Mails: linda.medlin@microbiaenvironnement.com (L.K.M.);

delphine.guillebault@microbiaenvironnement.com (D.G.)

4 UPMC Univ Paris 06, CNRS, Laboratoire de Biodiversité et Biotechnologies Microbiennes (LBBM), Sorbonne Universités, Observatoire Océanologique, F-66650 Banyuls/Mer, France; E-Mail: baudart@obs-banyuls.fr

5 SCIENION AG Volmerstr., 7b/12489 Berlin, Germany; E-Mail: weigel@scienion.de

6 Centre de Recherche de Saint Maurice, Immeuble le Dufy, Veolia Recherche et Innovation, 1 Place de Turenne, 94417 St. Maurice Cedex, France; E-Mail: karim.helmi@veolia.com

$\dagger$ These authors contributed equally to this work.

* Author to whom correspondence should be addressed; E-Mail: stefania.marcheggiani@iss.it; Tel.: +39-06-4990-2545; Fax: +39-06-4990-3603.

Academic Editor: Paul B. Tchounwou

Received: 8 October 2015 / Accepted: 8 October 2015 / Published: 23 October 2015 
We wish to make the following changes to the published article [1], agreed upon by all authors: Julia Baudart-Lenfant has been added as co-author. The corrected author list should therefore read: Stefania Marcheggiani, Emilo D’Ugo, Camilla Puccinelli, Roberto Giuseppetti, Anna Maria D’Angelo, Claudio Orlando Gualerzi, Roberto Spurio, Linda K. Medlin, Delphine Guillebault, Julia Baudart-Lenfant, Wilfried Weigel, Karim Helmi and Laura Mancini Author contributions are corrected accordingly:

\section{Author Contributions}

Author Contributions Stefania Marcheggiani and Laura Mancini participated in the design of the experiments, writing of the manuscript and in the discussion of results. Stefania Marcheggiani performed most of the experiments, and the interpretation of data with the scientific support of Delphine Guillebault, Julia BaudartLenfant and Linda K. Medlin, Roberto Spurio and Camilla Puccinelli provided scientific support to interpretation of diatom results. Emilo D'Ugo planned and performed the viral analysis. Roberto Giuseppetti carried out the water sampling. Anna Maria D'Angelo provided technical support for microbiological analysis. Karim Helmi provided the water concentration protocols. Wilfried Weigel provided scientific support for microarrays experiments. Claudio Orlando Gualerzi was responsible for coordination of sampling activities and management of data exchange.

All authors have read and approved the final manuscript. The authors would like to apologize for any inconvenience caused to readers by these changes

\section{Reference}

1. Marcheggiani, S.; D’Ugo, E.; Puccinelli, C.; Giuseppetti, R.; D’Angelo, A.M.; Gualerzi, C.O.; Spurio, R.; Medlin, L.K.; Guillebault, D.; Baudart-Lenfant, J.; Weigel, W.; Helmi, K.; Mancini, L. Detection of emerging and re-emerging pathogens in surface waters close to an urban area. Int. J. Environ. Res. Public Health 2015, 12, 5505-5527.

(C) 2015 by the authors; licensee MDPI, Basel, Switzerland. This article is an open access article distributed under the terms and conditions of the Creative Commons Attribution license (http://creativecommons.org/licenses/by/4.0/). 